\title{
Benefícios da participação paterna no ciclo gravídico puerperal para a consolidação do trinômio mãe-pai-filho
}

\author{
Benefits of paternal participation in the pregnancy-puerperal cycle for the consolidation of the \\ mother-father-child triad \\ Beneficios de la participación paterna en el ciclo embarazo-puerperal para la consolidación de la \\ tríada madre-padre-hijo
}

Recebido: 27/08/2021 | Revisado: 04/09/2021 | Aceito: 04/09/2021 | Publicado: 06/09/2021

João Felipe Tinto Silva

ORCID: https://orcid.org/0000-0003-3662-6673 Centro Universitário de Ciências e Tecnologia do Maranhão, Brasil

E-mail: felipetinto99@gmail.com

Emanuel Osvaldo de Sousa

ORCID: https://orcid.org/0000-0003-2825-4275 Universidade Estadual do Piauí, Brasil

E-mail: emanfisio@hotmail.com

Bruna Ribeiro Maia Alves

ORCID: https://orcid.org/0000-0003-3907-5889

Faculdade Brasileira Multivix, Brasil

E-mail: bubruna06@gmail.com

Larissa Dutra Cerqueira Ambrósio

ORCID: https://orcid.org/0000-0002-8983-8883

Faculdade Brasileira Multivix, Brasil

E-mail: larisdutraa@gmail.com

Ingrid Mikaela Moreira de Oliveira

ORCID: https://orcid.org/0000-0002-8901-362X

Universidade Estadual do Ceará, Brasil

E-mail: ingrid_lattes@hotmail.com

Andréia Ziviani Berger

ORCID: https://orcid.org/0000-0001-6992-439X

Faculdade Brasileira Multivix, Brasi

E-mail: andreiazb@gmail.com

Victória Maria Pontes Martins

ORCID: https://orcid.org/0000-0002-8281-0132

Centro Universitário INTA, Brasil

E-mail: victoriapontes2014@hotmail.com

Layanne Cavalcante de Moura

ORCID: https://orcid.org/0000-0003-2781-1076

Faculdade Integral Diferencial, Brasil

E-mail: layannecavalcante@hotmail.com

Kleber Luiz Santana dos Santos

ORCID: https://orcid.org/0000-0003-1781-6391

Universidade Cesumar, Brasi

E-mail: santanared@gmail.com

Laís Goldner Barcellos

ORCID: https://orcid.org/0000-0002-0236-257X

Faculdade Brasileira Multivix, Brasil

E-mail: laisgoldnerb@gmail.com

Saulo Leite de Paula

ORCID: https://orcid.org/0000-0002-9511-6115

Universidade Federal do Ceará, Brasi

E-mail: saulolp@yahoo.com.br

Yanna Cavalcante Martins

ORCID: https://orcid.org/0000-0002-1745-0847

Faculdade Uninassau, Brasil

E-mail: cavalcantedepaulay@gmail.com

Yuri Ferreira de Sousa

ORCID: https://orcid.org/0000-0001-6902-632X

Faculdade Cesma de Maracanaú, Brasi

E-mail: yuriferreirasousa123@gmail.com 


\author{
Michelle Quaresma Cardoso \\ ORCID: https://orcid.org/0000-0002-8621-8670 \\ Universidade Federal do Pará, Brasil \\ E-mail: michelle.card91@yahoo.com.br \\ Marcella Silva Cunha \\ ORCID: https://orcid.org/0000-0002-7476-2564 \\ Universidade Federal do Espirito Santo, Brasil \\ E-mail: marcellacunha1@ @otmail.com
}

\begin{abstract}
Resumo
O presente estudo teve como objetivo descrever os benefícios da participação paterna no ciclo gravídico puerperal para a consolidação do trinômio pai-mãe-filho. Trata-se de uma revisão integrativa da literatura, onde o levantamento do estudo foi realizado entre julho e agosto de 2021, através da BVS, com auxílio das bases de dados LILACS, BEDENF e Biblioteca Virtual SCIELO, utilizando os Descritores em Ciências da Saúde (DeCS): Pré-Natal; Relações Pai-Filho; e Período Pós-Parto. Após os critérios de inclusão e exclusão, 16 estudos forram selecionados para compor o presente estudo. Os resultados observados nos estudos mostram que a participação do homem deve ocorrer durante todo ciclo gravídico-puerperal, e deve estar em sintonia e de acordo com a companheira, e que durante esse ciclo o acompanhamento do homem/pai pode contribuir para a minimização do medo, anseios e ansiedade durante o pré-natal e outros sentimentos durante o período parturitivo, além de estabelecer um maior vínculo com a mãe e o futuro filho. No entanto, faz-se necessário que os profissionais da saúde durante o acompanhamento da gestante no pré-natal incentivem a participação da figura paterna no acompanhamento da sua parceira para a realização das consultas, tornando possível o vínculo da tríade mãe-pai-filho, a qual pode fortalecer melhor o relacionamento conjugal e familiar.
\end{abstract}

Palavras-chave: Pré-natal; Relações pai-filho; Período pós-parto.

\begin{abstract}
This study aimed to describe the benefits of paternal participation in the pregnancy-puerperal cycle for the consolidation of the father-mother-child triad. This is an integrative literature review, where the survey of the study was carried out between July and August 2021, through the VHL, with the aid of the LILACS, BEDENF and SCIELO Virtual Library databases, using the Health Sciences Descriptors (DeCS): Prenatal; Parent-Child Relationships; and Postpartum Period. After the inclusion and exclusion criteria, 16 studies were selected to compose this study. The results observed in the studies show that the participation of men must occur throughout the pregnancy-puerperal cycle, and must be in tune and in agreement with the partner, and that during this cycle, the monitoring of the man/father can contribute to the minimization of fear, anxieties and anxiety during prenatal care and other feelings during the parturition period, in addition to establishing a greater bond with the mother and the future child. However, it is necessary that health professionals, during the monitoring of pregnant women in prenatal care, encourage the participation of the father figure in monitoring their partner for the consultations, making the bond of the motherfather-child triad possible, which can better strengthen the marital and family relationship.
\end{abstract}

Keywords: Prenatal: Parent-child relationships; Postpartum period.

\title{
Resumen
}

Este estudio tuvo como objetivo describir los beneficios de la participación paterna en el ciclo embarazo-puerperal para la consolidación de la tríada padre-madre-hijo. Se trata de una revisión integradora de la literatura, donde la encuesta del estudio se realizó entre julio y agosto de 2021, a través de la BVS, con la ayuda de las bases de datos de la Biblioteca Virtual LILACS, BEDENF y SCIELO, utilizando los Descriptores de Ciencias de la Salud (DeCS): Prenatal; Relaciones entre padres e hijos; y período posparto. Después de los criterios de inclusión y exclusión, se seleccionaron 16 estudios para componer este estudio. Los resultados observados en los estudios muestran que la participación de los hombres debe darse a lo largo del ciclo embarazo-puerperal, y debe estar en sintonía y concordancia con la pareja, y que durante este ciclo, el seguimiento del hombre / padre puede contribuir a la minimización de miedos, ansiedades y ansiedades durante el prenatal y otros sentimientos durante el período del parto, además de establecer un mayor vínculo con la madre y el futuro hijo. Sin embargo, es necesario que los profesionales de la salud durante el seguimiento de la gestante en el prenatal fomenten la participación de la figura paterna en el seguimiento de su pareja para las consultas, posibilitando el vínculo de la tríada madre-padre-hijo, que puede fortalecer mejor la relación conyugal y familiar.

Palabras clave: Prenatal; Relaciones entre padres e hijos; Período posparto.

\section{Introdução}

A autonomia corporal é estabelecida por lei como um direito humano, da qual o indivíduo tem liberdade sobre o 
próprio corpo, vista a isso, a decisão de ter filhos ou não é de domínio privativo de uma mulher ou de um casal. Porém, quando a mulher se depara com a gravidez, sua autonomia fica relativizada, em vista da existência de outro ser, o nascituro, a qual também dispõe de seus direitos estabelecidos na constituição (Lopes et al., 2021).

Diante disso, a mulher necessita realizar um acompanhamento que se dá por meio de um conjunto de condutas que objetivam garantir que em todas as fases da gestação e do parto, doenças que podem desencadear nessa fase, tanto na mãe como no feto, sejam evitadas com o rastreamento precoce das mesmas, sendo este conjunto de condutas denominado de prénatal. Assim, tais medidas contribuem para a diminuição dos impactos à saúde de ambos, sendo a assistência pré-natal uma excelente medida preventiva, que pode ser também observada nos reflexos das taxas de mortalidade materna e neonatal (Cardoso et al., 2019).

Durante o pré-natal, é fundamental que os profissionais de saúde reconheçam que esse momento se constitui como oportunidade de aprendizado para a mulher e de fortalecimento de sua autonomia e bem-estar. Além disso, os profissionais que realizam o cuidado à mãe, bebê e sua família devem estar capacitados, com uma atuação baseada nas normas de atenção ao pré-natal do Ministério da Saúde (MS), com o propósito de um cuidado seguro, humanizado e justificado por evidências científicas, incluindo o direito à informação (Oliveira, Gonçalves \& Souza, 2018).

Assim, cabe destacar que o envolvimento paterno durante a gestação vai além da provisão material, compreendendose sua participação em atividades direcionadas às gestantes, aos preparativos com a chegada da criança, ao apoio emocional à mulher e a sua interação com o filho. Com essas atitudes, dá-se início às mudanças quanto à participação do homem no período gravídico da companheira, levando ao entendimento que essa fase não é restrita ao universo feminino (Cavalcanti \& Holanda, 2019).

Por meio da Lei $\mathrm{n}^{\circ} 11.108 / 2005$, é permitida a presença de um acompanhante, da vontade da gestante, durante o trabalho de parto, parto e pós-parto imediato. Desde então, evidencia-se um aumento da inclusão do pai ou outro acompanhante no processo de gestação. A participação paterna em grupos de gestantes é muito importante para a promoção do vínculo do casal, a mudança da concepção do papel do pai no cuidado com a mãe e o bebê, bem como o apoio à mulher não apenas no pré-natal, parto e puerpério, mas também na criação da criança (Rauber, Souza \& Telo, 2019).

Desse modo, a presença do homem/pai na assistência no período gravídico puerperal estabeleça um melhor relacionamento, uma vez que, o homem/pai é posto durante este período para que se tenha a promoção de vínculos afetivos e para que se identifique como pai, mesmo na antecedência da chegada do novo ser. No instante que o pai tem o reconhecimento a gravidez familiar e passa a se sentir incluso neste ciclo "gravídico", adquire uma nova percepção de cuidado e de ser cuidador (Silva, França, Pedrosa \& Rodrigues, 2019).

Com isso, uma assistência adequada e a interação com os serviços assistenciais do parto são cruciais para que se obtenha bons resultados durante este processo. Sendo no cotidiano que a interação entre o homem/pai, a família e os profissionais, promovem a construção da saúde. Assim, a Organização Mundial da Saúde (OMS) destaca o cuidado diante da atenção pré-natal, perinatal e puerperal e que estes precisam estar centralizados na família e ser direcionados para as necessidades não somente da mulher e de seu filho, mas do casal (Silva \& França, 2019).

Diante da importância do tema, o presente estudo tem como objetivo descrever os benefícios da participação paterna no ciclo gravídico puerperal para a consolidação do trinômio pai-mãe-filho.

\section{Metodologia}

O presente estudo trata-se de um estudo descritivo, do tipo revisão integrativa da literatura, de caráter qualitativo, visto que é definido como um tipo de investigação voltada para o aspecto qualitativo de uma determinada questão, os 
benefícios do pré-natal masculino na consolidação do trinômio mãe-pai-filho. A revisão de literatura permite aprofundar dentro de diversos autores e referenciais, sobre os discursos e principais temas abordados (Pereira et al., 2018).

Para a revisão integrativa da literatura foram percorridas as seguintes etapas: identificação do tema e seleção da questão norteadora, estabelecimento de critérios de inclusão e exclusão de estudos, categorização e avaliação dos artigos incluídos na revisão, interpretação dos resultados e a síntese do conhecimento dos principais resultados evidenciados na análise dos artigos incluídos (Mendes, Silveira \& Galvão, 2008).

O tema, determinou a construção da estratégia PICo, que representa uma acrômio para Paciente ou Problema (P), Interesse (I) e Contexto (Co), na qual foi utilizada para a geração da questão norteadora desta revisão integrativa da literatura: "Quais os benefícios da participação paterna no ciclo gravídico puerperal para a consolidação do trinômio pai-mãe-filho?".

O levantamento do estudo foi realizado entre julho e agosto 2021, onde a busca dos artigos foi realizada através da Biblioteca Virtual em Saúde (BVS), com auxílio das bases de dados Literatura Latino-Americana e do Caribe em Ciências da Saúde (LILACS), Base de Dados de Enfermagem (BDENF) e Scientific Electronic Library Online (SciELO).

Para a localização dos estudos relevantes, que respondessem à pergunta da pesquisa, utilizou-se os descritores: "PréNatal", "Relações Pai-Filho" e "Período Pós-Parto", localizados na lista dos Descritores em Ciências da Saúde (DeCS), disponíveis no portal da Biblioteca Virtual em Saúde em (http://decs.bvs.br/). Tais descritores foram cruzados utilizando os operadores booleanos “AND” para obtenção dos critérios de inclusão e exclusão.

Os critérios de inclusão estabelecidos para a seleção dos artigos foram: artigos completos publicados nas bases de dados elencadas, nos idiomas português e inglês, com recorte temporal de 2015 a 2021 e relacionados com a temática. Foram excluídos os estudos duplicados, incompletos, cartas ao editor, resumos, resenhas, monografias, dissertações, teses, e artigos publicados em anais de eventos, dentre aqueles que estão fora do recorte temporal.

\section{Resultados}

Foram identificados 625 artigos nas bases de dados. Após aplicação dos critérios de inclusão e exclusão, 538 foram excluídos, restando 87 artigos. Após a leitura dos títulos e resumos, foram excluídos 65 artigos, resultando num total de 22 publicações selecionadas. Destas, 04 foram excluídos por estarem duplicados nas bases de dados elencadas, resultando em 18 estudos. Após a leitura na integra, 02 foram excluídas por não responderem à questão norteadora, resultando em 16 artigos que foram selecionados para compor a presente revisão. O fluxograma com o detalhamento das etapas de pesquisa está apresentado a seguir na Figura 1. 
Figura 1. Fluxograma de identificação e seleção dos artigos, 2021.

\begin{tabular}{|c|c|c|c|}
\hline \multicolumn{4}{|c|}{ Artigos identificados nas bases de dados $(n=625)$} \\
\hline+ & + & + & + \\
\hline \multirow[t]{2}{*}{$\begin{array}{c}\text { BVS } \\
(n=344)\end{array}$} & $\begin{array}{l}\text { BEDENF } \\
(\mathrm{n}=104)\end{array}$ & $\begin{array}{c}\text { BEDENF } \\
(\mathbf{n}=71)\end{array}$ & $\begin{array}{l}\text { SCIELO } \\
(\mathrm{n}=106)\end{array}$ \\
\hline & & & 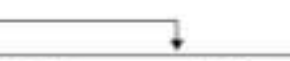 \\
\hline \multicolumn{3}{|c|}{ Artigos selecionados após a primeira análise $(n=87)$} & Artigos exchuidos \\
\hline \multicolumn{3}{|c|}{ I } & $(\mathrm{n}=538)$ \\
\hline \multicolumn{3}{|c|}{ Excluidos após a leitura dos títulos e resumos $(n=65)$} & \\
\hline \multicolumn{3}{|c|}{+} & Excluidos por \\
\hline \multicolumn{3}{|c|}{ Selecionados após a leitura do titulo e resumo $(n=22)$} & 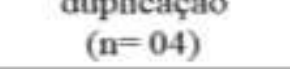 \\
\hline \multicolumn{3}{|c|}{ 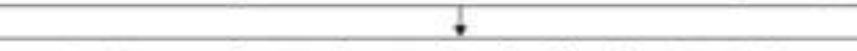 } & Antiaos excluidos \\
\hline \multicolumn{3}{|c|}{ Após a exclusăo de estudos duplicados $(n=18)$} & $\begin{array}{l}\text { Artigos excluidos } \\
\text { após }\end{array}$ \\
\hline \multicolumn{3}{|c|}{ Artigos selecionados para a revisāo $(n=16)$} & leitura na integra \\
\hline & & & $(\mathrm{n}=02)$ \\
\hline
\end{tabular}

Fonte: Pesquisa realizada (2021).

O Quadro 1 apresenta os estudos selecionados para a composição da presente revisão integrativa da literatura de forma mais detalhada, seguido as informações como autores e ano de publicação, título do artigo, objetivo e principais resultados.

Quadro 1. Distribuição dos artigos selecionados de acordo com os autores e ano de publicação, título do estudo, objetivo e principais resultados, 2021.

\begin{tabular}{|c|c|c|c|c|}
\hline $\mathbf{N}^{\mathbf{o}}$ & Autores/Ano & Título do Estudo & Objetivo & Principais resultados \\
\hline 01 & $\begin{array}{l}\text { Silva, Pinto \& } \\
\text { Martins } \\
\text { (2021) }\end{array}$ & $\begin{array}{l}\text { Transição para a } \\
\text { paternidade no período } \\
\text { pré-natal: um estudo } \\
\text { qualitativo }\end{array}$ & $\begin{array}{l}\text { Compreender as vivências dos } \\
\text { homens na transição para a } \\
\text { paternidade durante o período } \\
\text { pré-natal. }\end{array}$ & $\begin{array}{l}\text { O estudo reforça que as mudanças } \\
\text { comportamentais, emocionais, físicas e sociais } \\
\text { experienciadas pelos homens em resposta à } \\
\text { gravidez da parceira sinalizam a compreensão da } \\
\text { sua responsabilidade e um compromisso precoce } \\
\text { para com o bem-estar da sua família. }\end{array}$ \\
\hline 02 & $\begin{array}{l}\text { Menezes \& } \\
\text { Scorsolini- } \\
\text { Comin } \\
\text { (2019) }\end{array}$ & $\begin{array}{l}\text { Envolvimento paterno } \\
\text { na relação mãe-bebê: } \\
\text { revisão integrativa da } \\
\text { literatura }\end{array}$ & $\begin{array}{l}\text { Apresentar uma revisão } \\
\text { integrativa da literatura } \\
\text { científica, para identificar qual a } \\
\text { relevância do envolvimento } \\
\text { paterno para a relação mãe-bebê } \\
\text { desde a gestação, e outras } \\
\text { variáveis relacionadas a essa } \\
\text { dinâmica familiar. }\end{array}$ & $\begin{array}{l}\text { As evidências têm reforçado a importância da } \\
\text { presença paterna como integrante da rede de } \\
\text { apoio à mulher na gestação, parto e puerpério, e } \\
\text { para estabelecimento dos vínculos entre pai e } \\
\text { bebê/criança, fortalecimento da paternidade, } \\
\text { promoção da saúde mental do filho e bem-estar } \\
\text { da mulher. }\end{array}$ \\
\hline 03 & $\begin{array}{l}\text { Henz, Medeiros } \\
\text { \& Salvadori } \\
\text { (2017) }\end{array}$ & $\begin{array}{l}\text { A inclusão paterna } \\
\text { durante o pré-natal }\end{array}$ & $\begin{array}{l}\text { Investigar a participação } \\
\text { paterna durante o pré-natal em } \\
\text { um Centro de Atenção à Saúde } \\
\text { da Mulher. }\end{array}$ & $\begin{array}{l}\text { A participação paterna no período de pré-natal é } \\
\text { complexa e possui inúmeras variantes, pois } \\
\text { mesmo sendo estimulada pelos profissionais da } \\
\text { saúde depende também das questões econômicas, } \\
\text { culturais e familiares nas quais os homens estão } \\
\text { inseridos. }\end{array}$ \\
\hline 04 & $\begin{array}{c}\text { Braide } \text { et al. } \\
\text { (2019) }\end{array}$ & $\begin{array}{l}\text { Sou homem e pai sim! } \\
\text { (Re)construindo a } \\
\text { identidade } \\
\text { masculina a partir } \\
\text { da participação no }\end{array}$ & $\begin{array}{l}\text { Compreender como as } \\
\text { experiências de participação } \\
\text { ativa do homem no pré-natal e } \\
\text { no parto influenciam a } \\
\text { ressignificação das identidades }\end{array}$ & $\begin{array}{l}\text { O estudo aponta que a masculinidade não se } \\
\text { perde se houver uma participação do homem no } \\
\text { parto e cuidado dos filhos. Além disso, mostra } \\
\text { que participar do parto abre uma possibilidade de } \\
\text { aproximação do homem aos sistemas de saúde }\end{array}$ \\
\hline
\end{tabular}




\begin{tabular}{|c|c|c|c|c|}
\hline & & parto & masculinas. & $\begin{array}{l}\text { para a manutenção do bem-estar, ao invés de } \\
\text { necessariamente para o tratamento da doença. }\end{array}$ \\
\hline 05 & $\begin{array}{c}\text { Balica \& Aguiar } \\
\text { (2019) }\end{array}$ & $\begin{array}{c}\text { Percepções paternas } \\
\text { no } \\
\text { acompanhamento } \\
\text { do pré-natal }\end{array}$ & $\begin{array}{l}\text { Abordar a percepção dos pais } \\
\text { sobre os possíveis benefícios } \\
\text { proporcionados por sua } \\
\text { presença ao pré-natal. }\end{array}$ & $\begin{array}{l}\text { A pesquisa evidencia que a participação paterna } \\
\text { junto ao pré-natal é essencial para a boa } \\
\text { compreensão de tal papel, bem como para avaliar } \\
\text { a saúde em razão de doenças passíveis de } \\
\text { detecção com a realização de exames. Entretanto, } \\
\text { fatores culturais e profissionais tendem a afastar o } \\
\text { homem do pré-natal. }\end{array}$ \\
\hline 06 & $\begin{array}{l}\text { Santos } \\
(2018)\end{array}$ & $\begin{array}{l}\text { A importância do pai } \\
\text { no pré-natal e a } \\
\text { atuação do enfermeiro } \\
\text { de uma Unidade } \\
\text { Básica de Saúde de } \\
\text { João Pinheiro-MG. }\end{array}$ & $\begin{array}{l}\text { Investigar a importância do pai } \\
\text { no pré-natal e atuação do } \\
\text { enfermeiro na orientação no } \\
\text { processo gestacional. }\end{array}$ & $\begin{array}{l}\text { O estudo mostra que a participação do mesmo } \\
\text { contribui para aumento do vínculo com a gestante } \\
\text { e bebê e maior compreensão sobre a gestação. }\end{array}$ \\
\hline 07 & $\begin{array}{l}\text { Lopes et al. } \\
\text { (2021). }\end{array}$ & $\begin{array}{l}\text { Os benefícios do pré- } \\
\text { natal masculino para a } \\
\text { consolidação do } \\
\text { trinômio mãe-pai- } \\
\text { filho: uma revisão } \\
\text { integrativa }\end{array}$ & $\begin{array}{l}\text { Evidenciar, por meio de revisão } \\
\text { de literatura, a importância do } \\
\text { envolvimento paterno no } \\
\text { decorrer do ciclo gravídico- } \\
\text { puerperal, no favorecimento do } \\
\text { trinômio mãe-pai-filho. }\end{array}$ & $\begin{array}{l}\text { A participação do companheiro nas consultas de } \\
\text { pré-natal, contruibui na promoção da saúde e } \\
\text { facilitao diagnósticos de enfermidades, além de } \\
\text { fortalecer o vínculo, possibilitando um melhor } \\
\text { desenvolvimento fetal e um acompanhamento de } \\
\text { saúde do casal em todo o ciclo gravídico- } \\
\text { puerperal, }\end{array}$ \\
\hline 08 & $\begin{array}{l}\text { Holanda, } \\
\text { Castro, Aquin, } \\
\text { Pinheiro, Lopes } \\
\text { \& Martins } \\
\text { (2018) }\end{array}$ & $\begin{array}{l}\text { Influência da } \\
\text { participação do } \\
\text { companheiro no } \\
\text { pré-natal: } \\
\text { satisfação de } \\
\text { primíparas quanto } \\
\text { ao apoio no parto }\end{array}$ & $\begin{array}{l}\text { Correlacionar a satisfação de } \\
\text { primíparas quanto ao apoio e à } \\
\text { utilidade do companheiro } \\
\text { durante o processo de parto com } \\
\text { a sua presença e capacitação no } \\
\text { pré-natal. }\end{array}$ & $\begin{array}{l}\text { As associações significativas encontradas } \\
\text { demonstram a importância de estimular a } \\
\text { participação do parceiro no processo parturitivo e } \\
\text { a sua capacitação. }\end{array}$ \\
\hline 09 & $\begin{array}{l}\text { Ribeiro et al. } \\
\qquad(2018)\end{array}$ & $\begin{array}{l}\text { Percepção do pai } \\
\text { sobre a sua presença } \\
\text { durante o processo } \\
\text { parturitivo }\end{array}$ & $\begin{array}{l}\text { Descrever a percepção do pai } \\
\text { sobre sua presença durante o } \\
\text { processo parturitivo. }\end{array}$ & $\begin{array}{l}\text { No estudo os pais reconheceram o } \\
\text { acompanhamento às companheiras em trabalho } \\
\text { de parto como positivo, pois puderam contribuir } \\
\text { proporcionando-lhes apoio, segurança, confiança, } \\
\text { conforto e bem-estar físico e emocional. }\end{array}$ \\
\hline 10 & $\begin{array}{l}\text { Francisco, } \\
\text { Souza, Vitório, } \\
\text { Zampieri \& } \\
\text { Gregório } \\
\text { (2015) }\end{array}$ & $\begin{array}{l}\text { Percepções dos pais } \\
\text { sobre suas vivências } \\
\text { como acompanhantes } \\
\text { durante o parto e } \\
\text { nascimento }\end{array}$ & $\begin{array}{l}\text { Conhecer as percepções do pai } \\
\text { acerca de sua vivência durante o } \\
\text { processo de nascimento do } \\
\text { filho. }\end{array}$ & $\begin{array}{l}\text { Para os pais, estar com seu filho e sua mulher é } \\
\text { um momento singular, importante para fortalecer } \\
\text { o vínculo e dar apoio e suporte à mulher. Porém, } \\
\text { o desconhecimento acerca do processo de } \\
\text { nascimento gera sentimentos negativos e } \\
\text { impotência no trabalho de parto, que podem ser } \\
\text { superados pelo compartilhamento de } \\
\text { conhecimentos entre enfermeiro e pais. }\end{array}$ \\
\hline 11 & $\begin{array}{l}\text { Melo, Angelo, } \\
\text { Pontes \& Brito } \\
\qquad(2015)\end{array}$ & $\begin{array}{l}\text { Conhecimento de } \\
\text { homens sobre o } \\
\text { trabalho de parto e } \\
\text { nascimento }\end{array}$ & $\begin{array}{l}\text { Analisar a percepção do } \\
\text { homem/companheiro quanto à } \\
\text { sua presença na sala de parto } \\
\text { durante o nascimento de seu } \\
\text { filho }\end{array}$ & $\begin{array}{l}\text { Os homens demonstraram reconhecer os sinais do } \\
\text { trabalho de parto e declararam o choro do recém- } \\
\text { nascido como sinal de vida. Assim, a presença do } \\
\text { homem na sala de parto favorece as relações } \\
\text { interpessoais no momento do nascimento do } \\
\text { filho. }\end{array}$ \\
\hline 12 & $\begin{array}{l}\text { Petito, Cândido, } \\
\text { Ribeiro \& Petito } \\
\qquad \text { (2015) }\end{array}$ & $\begin{array}{l}\text { A importância da } \\
\text { participação do pai no } \\
\text { ciclo gravídico } \\
\text { puerperal: uma } \\
\text { revisão bibliográfica }\end{array}$ & $\begin{array}{l}\text { Levantar produções científicas } \\
\text { sobre a importância da } \\
\text { participação do pai no ciclo } \\
\text { gravídico puerperal. }\end{array}$ & $\begin{array}{l}\text { O estudo evidencia que A participação do pai } \\
\text { durante o ciclo gravídico-puerperal é de total } \\
\text { relevância, trazendo para mulher segurança e } \\
\text { acalmando a mesma, fazendo com que assim ela } \\
\text { se sinta mais feliz e tranquila nesse período, } \\
\text { diminuindo o uso de intervenções e medicações } \\
\text { durante o parto, possibilitando dessa forma que } \\
\text { ele adquira um maior vínculo com a mãe e o } \\
\text { bebê. }\end{array}$ \\
\hline
\end{tabular}




\begin{tabular}{|c|c|c|c|c|}
\hline 13 & $\begin{array}{l}\text { Oliveira \& } \\
\text { Souza } \\
(2017)\end{array}$ & $\begin{array}{l}\text { A participação do pai } \\
\text { no ciclo gravídico } \\
\text { puerperal }\end{array}$ & $\begin{array}{l}\text { Analisar a participação do pai } \\
\text { no ciclo gravídico puerperal a } \\
\text { partir de pesquisas publicadas } \\
\text { sobre o tema. }\end{array}$ & $\begin{array}{l}\text { Referente à participação paterna durante o parto e } \\
\text { nascimento, o estudo evidencia importantes } \\
\text { benefícios resultantes da presença do pai, a saber: } \\
\text { o aumento dos partos vaginais/naturais, } \\
\text { diminuição do tempo de trabalho de parto e do } \\
\text { uso de instrumentos para o parto vaginal e o } \\
\text { número de recém-nascidos com baixo índice de } \\
\text { Apgar no } 5^{\circ} \text { minuto de vida, ajudando assim nos } \\
\text { cuidados com a mulher e o recém-nascido no } \\
\text { período de pós-parto. }\end{array}$ \\
\hline 14 & $\begin{array}{l}\text { Queiroz, } \\
\text { Stermer \& } \\
\text { Moura } \\
(2021)\end{array}$ & $\begin{array}{l}\text { Participação paterna } \\
\text { na gestação, parto e } \\
\text { puerpério: uma } \\
\text { revisão integrativa }\end{array}$ & $\begin{array}{l}\text { Realizar uma revisão integrativa } \\
\text { de literatura a fim de se } \\
\text { problematizar a participação do } \\
\text { homem/pai na assistência a } \\
\text { mulher durante todo o processo } \\
\text { gestacional e sua influência na } \\
\text { construção da relação paimãe- } \\
\text { filho. }\end{array}$ & $\begin{array}{l}\text { O estudo aponta que a participação masculina na } \\
\text { gestação, parto e puerpério deve ser reforçada e } \\
\text { estimulada, principalmente pelos profissionais da } \\
\text { saúde, já que traz benefícios a saúde da família e } \\
\text { reforça a tríade paimãe-filho. }\end{array}$ \\
\hline 15 & $\begin{array}{l}\text { Silva, França, } \\
\text { Pedrosa \& } \\
\text { Rodrigues } \\
\text { (2019) }\end{array}$ & $\begin{array}{l}\text { A participação do } \\
\text { homem/pai no } \\
\text { Acompanhamento da } \\
\text { assistência } \\
\text { No período gravídico } \\
\text { puerperal }\end{array}$ & $\begin{array}{l}\text { Descrever a importância da } \\
\text { presença do homem/pai no } \\
\text { acompanhamento da assistência } \\
\text { gravídico puerperal. }\end{array}$ & $\begin{array}{l}\text { Diante dos resultados é fundamental que os } \\
\text { homens possuam facilidade de acesso para estes } \\
\text { serviços e se sintam acolhidos e motivados para } \\
\text { terem sua } \\
\text { participação nas consultas. É crucial aprender o } \\
\text { significado e bem como as atribuições da } \\
\text { gestação e das consultas de pré-natal ao que se } \\
\text { relaciona a família, sobretudo ao pai. }\end{array}$ \\
\hline 16 & $\begin{array}{l}\text { Couto, Gomes, } \\
\text { Vilela, Pereira, } \\
\text { França \& } \\
\text { Nogueira } \\
\text { (2020) }\end{array}$ & $\begin{array}{l}\text { A presença do genitor } \\
\text { no pré-natal: um } \\
\text { estudo de } \\
\text { representações sociais } \\
\text { com gestantes }\end{array}$ & $\begin{array}{l}\text { Analisar as representações } \\
\text { sociais da presença do genitor } \\
\text { no pré-natal para as mulheres } \\
\text { gestantes. }\end{array}$ & $\begin{array}{l}\text { As representações sociais das gestantes sobre a } \\
\text { presença pai nas consultas de pré-natal foram } \\
\text { elaboradas a partir da negação, evidenciadas nos } \\
\text { discursos do grupo no termo "não". }\end{array}$ \\
\hline
\end{tabular}

Fonte: Pesquisa realizada (2021)

\section{Desenvolvimento da identidade paterna}

Silva, Pinto e Martins (2021) relatam que a formação da identidade paterna é despertada pelas experiências da infância e pela presença ou ausência de figuras paternas na vida da criança. Neste sentido, a vivência de uma experiência deficiente ou insatisfatória com o seu próprio pai influencia o homem a adotar uma relação mais afetiva com seu próprio filho. Com isto, os homens sentem-se num espaço mais emocional durante a gestação da parceira, o que o faz se sensibilizar e realizar o acompanhamento da mulher no pré-natal.

Desde a gestação, o envolvimento paterno pode ser observado a partir de diferentes comportamentos, como preocupações em relação ao bebê e à mãe, bem como sua participação direta na gestação e a interação pai-bebê. Assim, o estabelecimento de uma maior vinculação entre pai e filho durante a gravidez potencializa o desenvolvimento da paternidade e desse vínculo após o nascimento, repercutindo positivamente em um maior envolvimento e na maior proximidade dessa díade. A participação paterna na fase da gravidez possibilita que o homem se integre melhor ao processo, o que também pode repercutir positivamente em uma melhor vinculação com a mulher, com menos conflitos e maior satisfação em termos do relacionamento amoroso estabelecido (Menezes \& Scorsolini-Comin, 2019).

Atualmente percebem-se mudanças no que diz respeito às modificações que ocorreram durante o período gestacional, onde o homem passa a participar mais ativamente da gravidez. Estas mudanças colaboraram para que ocorra o aumento do vínculo paterno tanto com sua companheira quanto com o bebê, desenvolvendo assim um maior envolvimento afetivo familiar. Assim, incluir o homem durante o pré-natal é uma estratégia que proporciona maior interesse à gestação estimulando o homem 
a ter um maior cuidado com a mulher e o bebê (Henz, Medeiros \& Salvadori, 2017).

No entanto, a paternidade sendo considerada uma construção social perene, com influência de aspectos subjetivos e socioculturais, a experimentação e a vivência do nascimento do filho, não como expectador, mas como participante direto, proporciona aos homens um novo olhar para os significados atribuídos a paternidade e masculinidade (Braide et al., 2019). Vista a isso, a identidade paterna é despertada, e o homem como futuro pai, tende a realizar várias mudanças, as quais podem ser sentidas durante a identificação paterna, que podem ser encaradas como estratégias preparatórias para assumir o papel paterno. Assim, integram mudanças comportamentais: cessação de tabagismo, condução cuidadosa, atitude mais defensiva nos desportos radicais ou outros cuidados consigo próprios, com o objetivo de assegurar que estará presentes na vida do filho (Silva, Pinto \& Martins, 2021).

Braide et al. (2019) cita em seu estudo que diante da importância do papel masculino na consolidação do trinômio mãe-pai-filho, emerge a necessidade de suscitar momentos e espaços que possibilitem a ressignificação das identidades masculinas, uma vez que, a paternidade é um momento propício para envolver o homem com a possibilidade do prazer em relação à gravidez, ao parto e a relacionamentos mais equitativos no cotidiano doméstico.

\section{Os benefícios da figura paterna no acompanhamento ao pré-natal}

Tradicionalmente, o envolvimento paterno com a família é marcado por certa distância entre o comportamento paterno considerado ideal e o comportamento real, com a figura paterna pouco se envolvendo no cuidado prestado aos filhos e nas tarefas domésticas. O homem que acompanha sua parceira nas consultas de pré-natal já se prepara emocionalmente para exercer a paternidade, além de tornar o momento da gestação mais humanizado. É necessário que o homem proporcione à sua companheira apoio emocional, para que esta se sinta mais segura, fazendo com que o casal possa compartilhar as alegrias do nascimento, o que gera maior proximidade e intensificação do relacionamento (Henz, Medeiros \& Salvadori, 2017).

Pesquisas já realizadas acerca da presença do pai na gestação evidenciam que este pode apoiar a companheira de diversas formas. Pode acompanhá-la nas consultas e exames; elogiar, mostrando sua percepção, as modificações no seu corpo; conversar mais com ela, sendo compreensivo e prestativo; ajuda-la com as tarefas domésticas, principalmente se ela trabalhar fora ou o casal já tiver outros filhos. O contato do pai com os exames, como as ecografias, ajuda na materialização da presença do novo filho, iniciando o vínculo emocional ainda na gestação. A presença paterna também pode dinamizar as consultas de pré-natal, tidas como rotineiras, burocráticas, meramente informativas e pouco participativas. Assim, é fundamental que a enfermagem desenvolva ações que permitam a participação efetiva do homem, para que exerça paternidade mais responsável e para ajudar a sua companheira durante essa fase. O pré-natal deve ser o momento em que tanto a mulher, quanto o homem, devem ser ouvidos em suas necessidades (Balica \& Aguiar, 2019).

Para Santos (2018) a participação do pai durante o pré-natal torna-se cada vez mais frequente, e a sua presença deve ser estimulada durante as atividades de consulta de grupo, além de ajudar a preparar o casal para o momento do parto.

Com esta participação, o homem torna a sua companheira o foco de atendimento, além de fortalecer seus potencias e conhecimento para auxiliar a gestante, colocando-o em uma posição ativa e não somente de expectador no que diz respeito ao nascimento. Neste sentido, para que ocorra adesão paterna ao pré-natal é necessário que os profissionais criem atividades e estratégias para que os homens façam os seus exames preventivos e tenham um acompanhamento na mesma época em que as mulheres estejam fazendo o pré-natal. Tendo, assim, a oportunidade de realizar um acompanhamento do pai durante a gestação (Henz, Medeiros \& Salvadori, 2017).

Além disso, para Lopes et al. (2021) no acompanhamento da gestante ao pré-natal, o comprometimento consciente e vigoroso do pai/parceiro, torna-se um fator preditivo para a abertura de concepções abarcadas historicamente de que, a 
paternidade só inicia com o nascimento da criança ou quando ela já está crescida. Dessa forma, a gravidez torna-se também é uma abordagem para o homem, a qual deve acontecer a sua estimulação de participação como parceiro/pai durante todo o ciclo, sendo imprescindível para o bem-estar biopsicossocial da mãe, do bebê e dele próprio, tendo o pré-natal como o momento apropriado para criação de um vínculo mais afetivo.

Vale ressaltar que o envolvimento do parceiro, quando estimulado efetivamente pelo profissional de saúde, contribui para as tomadas de decisão compartilhadas entre o casal acerca do tipo de parto, da escolha da maternidade, assim como a efetivação de maior conhecimento relativo aos sinais de risco durante a gestação, parto e puerpério (Holanda, Castro, Aquin, Pinheiro, Lopes \& Martins 2018).

\section{A presença do pai no trabalho de parto}

A mulher que é preparada desde o pré-natal acerca de orientações relativas à gestação, parto e puerpério, vivenciará esses momentos com maior segurança e satisfação, fato que pode se estender ao seu parceiro. Nesse contexto, planejar o parto contribui positivamente para a preparação da mulher durante o trabalho de parto e parto, aprimorando as dimensões acerca da segurança, efetividade, satisfação e empoderamento da mulher. Já os pais apresentam grandes expectativas e curiosidade relacionadas ao seu papel durante o trabalho de parto e demonstram cada vez mais interesse e empenho em participar e se envolver nas sessões formativas de preparação para o parto (Holanda, Castro, Aquin, Pinheiro, Lopes \& Martins, 2018).

Ribeiro et al. (2018) relatam que o aconchego e a interação entre os casais revelam-se como elementos importantes para a ascensão da humanização durante o trabalho de parto, e que a mesma se fundamenta em princípios éticos e humanos tendo, como premissa, a estima e concedendo, ainda, suporte emocional às suas companheiras. Essa demonstração de afeto espontâneo e natural por eles ofertada favorece a satisfação, pois as parturientes se sentem acolhidas e amparadas, provocando superioridade em confiança e segurança nos trabalhos de pré-parto, parto e pós-parto, resultando em conforto, além de propiciar o protagonismo da mulher diante do processo parturitivo.

Francisco, Souza, Vitório, Zampieri e Gregório (2015) evidenciam que a mulher, ao permanecer sozinha durante o trabalho de parto e parto, pode apresentar medo, ansiedade, apreensão e tensão que podem aumentar a dor. A presença de alguém de sua confiança evita tais sentimentos, quebrando o ciclo tensão, medo e dor, controlando-a, reduzindo a necessidade de medicação, além de deixá-las mais seguras e confiantes e diminuir a duração do trabalho de parto e a incidência de depressão pós-parto e cesariana. A participação do acompanhante contribui para a humanização da assistência, além de ser uma prática baseada em evidências científicas. Além disso, os pais percebem que estar nesse momento é estímulo e fortalece o potencial da mulher no momento de parir, podendo diminuir intercorrências durante o processo de nascimento. Consideram-se parte da rede de apoio à mulher, ajudando-a a enfrentar as dificuldades, estando presente, apoiando-a emocionalmente, fazendo massagens, orientando sobre a respiração, segurando sua mão, estimulando-a, confortando e dando segurança.

Holanda, Castro, Aquin, Pinheiro, Lopes e Martins (2018) citam que a presença do parceiro da parturiente no trabalho de parto traz benefícios acalmar, encorajar, transmitir força, distrair e proporcionar apoio a mulher e a equipe.

Além disso, um fato vivenciado pelo pai, independentemente de qual seja a percepção do homem nesse papel de acompanhante, o nascimento o remete a uma experiência singular e importante em sua vida. Esse é um momento em que a metamorfose da vida masculina se concretiza. Estar presente no parto, colocar seu filho no colo, ouvir seu choro e constatar que está bem traz para os pais uma nova forma de olhar a vida. O elo entre pai e filho, iniciado no parto, contribui para a formação de vínculo, representação de laços de família, construção do papel de pai e afirmação da paternidade (Francisco, Souza, Vitório, Zampieri \& Gregório, 2015).

Melo, Angelo, Pontes e Brito (2015) relatam que o homem/pai reconhece o choro do recém-nascido como desfecho 
do trabalho de parto e anúncio de vida. O choro do neonato ganhou destaque no contexto dos depoimentos, desenvolvendo nos entrevistados a concepção de que o processo parturitivo representa a vida. Ao presenciar o nascimento do filho, ao escutar o seu choro, os pais se emocionaram e ressaltaram vivenciar sentimentos de felicidade, alegria e sensação de bem estar. Além de considerar o nascimento e o choro do recém-nascido um valor simbólico para o pai.

No âmbito da presença do homem na sala de parto, considera-se necessário que profissionais de saúde lidem com o fenômeno do nascimento como um evento repleto de sensações. Assim sendo, os envolvidos, companheiro e parturiente, podem expressar a sua sensibilidade e dar espaço as suas emoções, pois como seres humanos são dotados de subjetividade e sentimentos que uma vez expressados, carecem de respeito e cuidado (Couto, Gomes, Vilela, Pereira, França \& Nogueira, 2020).

\section{O envolvimento paterno no puerpério}

O puerpério é um período muito importante no ciclo gravídico puerperal, pois durante ele, tudo o que foi planejado em relação aos cuidados com o recém-nascido são colocados em prática, o pai, neste momento o intermediário das relações entre a mãe e o filho. O companheiro deve se mostrar acessível para cuidar tanto da criança, como das tarefas domésticas, evitando assim, o desgaste emocional da mulher, desenvolvendo o vínculo e a prática da paternidade. Estudos demonstram que quando o homem se mostra acessível a ajudar a esposa nos cuidados com o recém-nascido, ele está demonstrando que sabe o quanto a mulher e a criança precisam que ele dedique parte do seu tempo aos mesmos, diminuindo assim, os sentimentos negativos da mulher, facilitando o convívio familiar (Petito, Cândido, Ribeiro \& Petito, 2015).

Ainda no puerpério, sobre as questões relacionadas ao relacionamento homem-mulher e o relacionamento mulherbebê, também que estes são potenciais influenciadores do processo de adaptação à paternidade. No referido período o pai confronta suas expectativas com a concretização da presença do filho, deparando-se com as dificuldades acarretadas pelas responsabilidades com a criança e a dependência dos pais (Ribeiro et al., 2018).

Segundo Oliveira e Souza (2017), durante o período pós-parto, seja ainda em ambiente hospitalar ou no doméstico, o pai atua como suporte emocional e participa dos primeiros momentos junto à nova família. Ele quem auxilia sua esposa nas atividades que ainda são novas para ambos, como amamentação e cuidados com o bebê. Desta forma, os estudos pesquisados mencionam a importância da participação do pai no ciclo gravídico puerperal e que os profissionais de saúde sabem destes benefícios. Porém, a participação ainda se encontra em um lento crescimento e a deficiência física das maternidades é um dos principais problemas.

Desse modo, Queiroz, Stermer e Moura (2021) propõem que a presença do homem/pai deve acontecer ao logo de todo o ciclo gravídico-puerperal, devendo estar sempre em sintonia e conforme a companheira. Pois, além de favorecer com a relação, a participação masculina é de extrema importância na manutenção da saúde da gestante. Participação nas práticas educativas de pré-natal, parto e nos cuidados estabelecidos a mulher e ao filho no puerpério são de grande serventia para a homeostase materna.

Vista a isso, dá se a importância dos profissionais de saúde como facilitadores dessa participação, enfatizando a necessidade do homem/pai na gravidez, excluindo a ideia de que o homem é exclusivo para ser provedor das necessidades materiais, além de fazer com que se sinta parte do processo gravídico (Silva, França, Pedrosa \& Rodrigues, 2019).

\section{Considerações Finais}

O presente estudo evidencia que a participação do companheiro durante o período gravídico puerperal é essencial, uma vez que, é evidente a importância do estabelecimento do vínculo na tríade mãe-pai-filho. Dessa maneira, faz-se necessária 
o desenvolvimento de orientações ao homem/pai em relação aos seus direitos de acompanhante durante a gestação da sua companheira a partir das consultas pré-natal, no momento do parto e no puerpério, aprimorando assim a criação de um maior vínculo da paternidade e melhores condições de adaptação relacionadas as mudanças que ocorrem neste período, relativas ao ser pai dentro da sociedade e na sua família.

No entanto, são sugerido que futuros trabalhos enfatizem melhor a percepção da gestante acerca da participação do parceiro/pai durante o período gravídico puerperal, com vistas a traçar quais benefícios a gestante percebe nesse período, bem como os fatores que interferem no acompanhamento paterno durante a gravidez e o puerpério.

Por fim, faz-se necessário que os profissionais da saúde durante o acompanhamento da gestante no pré-natal incentivem a participação da figura paterna no acompanhamento da sua parceira para a realização das consultas, tornando possível o vínculo da tríade mãe-pai-filho, a qual pode fortalecer melhor o relacionamento conjugal e familiar.

\section{Referências}

Balica, L. O., Aguiar, R. S. (2019). Percepções paternas no acompanhamento do pré-natal. Rev. Aten. Saúde, São Caetano do Sul, $17(61)$ : 114-126.

Braide, A. S. G. et al. (2019). Sou homem e pai sim! (Re)construindo a identidade masculina a partir da participação no parto. Rev Panam Salud Publica, 42(07): e190.

Cardoso, S. L. et al. (2019). Ações de promoção para saúde da gestante com ênfase no pré-natal. Revista Interfaces, 7(1): 180-186.

Cavalcanti, T. R. L., Holanda, V. R. (2019). Participação paterna no ciclo gravídico-puerperal e seus efeitos sobre a saúde da mulher. Enferm. Foco, 10(1): 9398.

Couto, P. L. S., Gomes, A. M. T., Vilela, A. B. A., Pereira, S. S. C., França, L. C. M., Nogueira, V. P. F. (2020). A presença do genitor no pré-natal: um estudo de representações sociais com gestantes. Rev enferm UERJ, 28:e43407, 1-9.

Francisco, B. S., Souza, B. S., Vitório, M. L., Zampieri, M. F. M., Gregório, V. R. P. (2015). Percepções dos pais sobre suas vivências como acompanhantes durante o parto e nascimento. Rev Min. Enferm., 19(3): 576-583.

Henz, G. S., Medeiros, C. R. G., Salvadori, M. (2017). A inclusão paterna durante o pré-natal. Rev Enferm Atenção Saúde, 6(1):52-66.

Holanda, S. M., Castro, R. C. M. B., Aquin, P. S., Pinheiro, A. K. B., Lopes, L. G., Martins, E. S. (2018). Influência da participação do parceiro no pré-natal: satisfação dos primipapers no apoio ao trabalho. Texto \& Contexto - Enfermagem, 27(2), e3800016.

Lopes, G. S. et al. (2021). Os benefícios do pré-natal masculino para a consolidação do trinômio mãe-pai-filho: uma revisão integrativa. REVISA, 10(1): 22-38.

Melo, R. M., Angelo, B. H. B., Pontes, C. M., Brito, R. S. (2015). Conhecimento de homens sobre o trabalho de parto e nascimento. Esc Anna Nery, 19(3):454-459.

Mendes, K. D. S., Silveira, R. C. C. P., Galvão, C. M. (2008). Revisão integrativa: método de pesquisa para a incorporação de evidências na saúde e na enfermagem. Texto \& Contexto - Enfermagem. 17(4), 758-764.

Menezes, M. S. L., Scorsolini-Comin, F. (2019). Envolvimento paterno na relação mãe-bebê: revisão integrativa da literatura. Psicologia em Revista, 25(1), 19-39.

Oliveira, B. K. S., Gonçalves, T. P., Souza, K. V. (2018). Direitos da mulher no ciclo gravídico-puerperal: conhecimento das gestantes em uma unidade básica de saúde. Enfermagem Obstétrica, 5:e93, 1-8.

Oliveira, T. M. S., Souza, F. M. L. C. (2017). A participação do pai no ciclo gravídico puerperal. Revista Cultural e Científica do UNIFACEX, 15(1): 1-10.

Pereira, A. S. (2018). Metodologia da pesquisa científica. UFSM. https://repositorio.ufsm.br/bitstream/handle/1/15824/Lic_Computacao_MetodologiaPesquisa-Cientifica.pdf?sequence $=1$.

Petito, A. D. C., Cândido, A. C. F., Ribeiro, L. O., Petito, G. (2015). A importância da participação do pai no ciclo gravídico puerperal: uma revisão bibliográfica. Rev. Eletr. da Faculdade de Ceres, 4(1): 1:14.

Queiroz, O. L., Stermer, P. R. R., Moura, D. S. C. (2021). Participação paterna na gestação, parto e puerpério: uma revisão integrativa. Brazilian Journal of Development, Curitiba, 7(4), p. 39497-39508.

Rauber, C. S., Souza, E. N., Telo, S. V. (2021). Percepções de mulheres sobre a participação paterna em grupos de gestantes. Journal Health NPEPS, 6(1):272-288.

Ribeiro, J. F., et al. (2018). Percepção do pai sobre a sua presença durante o processo parturitivo. Rev enferm UFPE on line., 12(6):1586-92.

Rodrigues, E. S. R. C., Torquato, J. A., Davim, R. M. B., Oliveira, L. F. M., Alves, E. S. R. C., Nóbrega, M. F. (2016). Percepção das mulheres sobre seus 
Research, Society and Development, v. 10, n. 11, e475101119927, 2021

(CC BY 4.0) | ISSN 2525-3409 | DOI: http://dx.doi.org/10.33448/rsd-v10i11.19927

direitos no ciclo gravídico-puerperal. Rev enferm UFPE on line, 10(5):1796-804.

Santos, M. L. P. (2018). A importância do pai no pré-natal e a atuação do enfermeiro de uma unidade básica de saúde de João Pinheiro-MG. Periódicos da FCPJ, 1(1): 1-38

Silva, C., Pinto, C., Martins, C. (2021). Transição para a paternidade no período pré-natal: um estudo qualitativo. Ciênc. Saúde Colet., 26(02): 465-474.

Silva, M. C., França, A. M. B., Pedrosa, A. K., Rodrigues, A. P. R. A. (2019). A participação do homem/pai no acompanhamento da assistência no período gravídico puerperal. Ciências Biológicas e de Saúde Unit, 5(3): 105-116. 